\title{
Avoiding Hospitalizations for Ambulatory Care-Sensitive Conditions
}

Ann Fam Med 2013:iii. doi:10.1370/afm.1555.

The Annals of Family Medicine encourages readers to develop a learning community of those seeking to improve health care and health through enhanced primary care. You can participate by conducting a RADICAL journal club and sharing the results of your discussions in the Annals online discussion for the featured articles. RADICAL is an acronym for Read, Ask, Discuss, Inquire, Collaborate, Act, and Learn. The word radical also indicates the need to engage diverse participants in thinking critically about important issues affecting primary care and then acting on those discussions. ${ }^{1}$

\section{HOW IT WORKS}

In each issue, the Annals selects an article or articles and provides discussion tips and questions. We encourage you to take a RADICAL approach to these materials and to post a summary of your conversation in our online discussion. (Open the article online and click on "TRACK Comments: Submit a response.") You can find discussion questions and more information online at: http://www.AnnFamMed.org/AJC/.

\section{CURRENT SELECTION}

\section{Article for Discussion}

Freund T, Campbell SM, Geissler S, et al. Strategies for reducing potentially avoidable hospitalizations for ambulatory care-sensitive conditions. Ann Fam Med. 2013;11(4):363-370.

\section{Discussion Tips}

Health policy researchers have touted the effect of primary care in helping patients to avoid hospitalizations for ambulatory care-sensitive conditions. ${ }^{2}$ But how does this happen? This study asks family physician respondents to consider the mechanisms for this important function.

\section{Discussion Questions}

- What question is asked by this study and why does it matter?
- How does this study advance beyond previous research and practice on this topic?

- How strong is the study design for answering the question?

- Were there sufficiently diverse data sources and perspectives brought to the analysis to give you confidence in the truthfulness and transportability of the findings?

- What are the main study findings?

-What factors identified in this study as important to preventing avoidable hospitalizations seem particularly relevant? What others would you add?

- In your setting, how might you:

1. Identify and keep track of potentially avoidable hospitalizations (including perhaps readmissions) for ambulatory care-sensitive conditions?

2. How might you systematically look back at these for things that you might have done to avoid the hospitalization?

3. How might you take what you are learning and apply it prospectively?

4. How might you maximize your ongoing learning?

5. In an era in which hospitals and health care systems may be penalized for readmissions and for avoidable hospitalizations, how might you work with payers and health care system leaders to invest in your efforts to reduce avoidable hospitalizations?

6. How might you share your methods and emerging findings to maximize your learning?

7. When might this process cross over from quality improvement to research?

- How might this study change your practice? Policy? Education? Research?

-What researchable questions remain?

\section{References}

1. Stange KC, Miller WL, McLellan LA, et al. Annals Journal Club: It's time to get RADICAL. Ann Fam Med. 2006;4(3):196-197.

2. Rosano A, Loha CA, Falvo R, et al. The relationship between avoidable hospitalization and accessibility to primary care: a systematic review. Eur J Public Health. 2013;23(3):356-360. 